\title{
Tailored-medicine project aims for ethnic balance
}

\author{
Massive study seeks to succeed where others failed, but faces tight deadline and \\ questions about strategy.
}

\section{BY SARA REARDON}

$\mathrm{T}$ he clock is ticking for experts charged with designing a US government programme to collect genetic, physiological and other health data from one million volunteers over the next two decades. The plan for the effort, part of the US\$215-million Precision Medicine Initiative (PMI) announced in January, is due in the next few weeks - a daunting deadline, in part because the effort's priorities include filling racial and socio-economic gaps left by other long-term studies.

The US National Institutes of Health (NIH), which is leading the PMI, is weighing ambition against a desire to avoid the mistakes that torpedoed its National Children's Study, which would have tracked 100,000 children from birth to adulthood. The agency abandoned that effort in December 2014, after recruiting just 5,700 participants at a cost of US $\$ 1.3$ billion. It cited overly complex study design and goals.

Clinical trials in the United States have historically relied on enrolling white participants from higher socio-economic levels, despite the fact that ethnic minorities make up about $40 \%$ of the country's population. Of the 58,160 lung-disease studies published between 1993 and 2013, for example, less than $5 \%$ reported the inclusion of participants from minority ethnic groups (E. G. Burchard et al. Am. J. Respir. Crit. Care Med. 191, 514-521; 2015). The disparity is especially problematic because many diseases are more prevalent among certain ethnic groups, and ethnicity may also influence which therapies are effective, says Esteban Burchard, a physician scientist at the University of California, San Francisco.

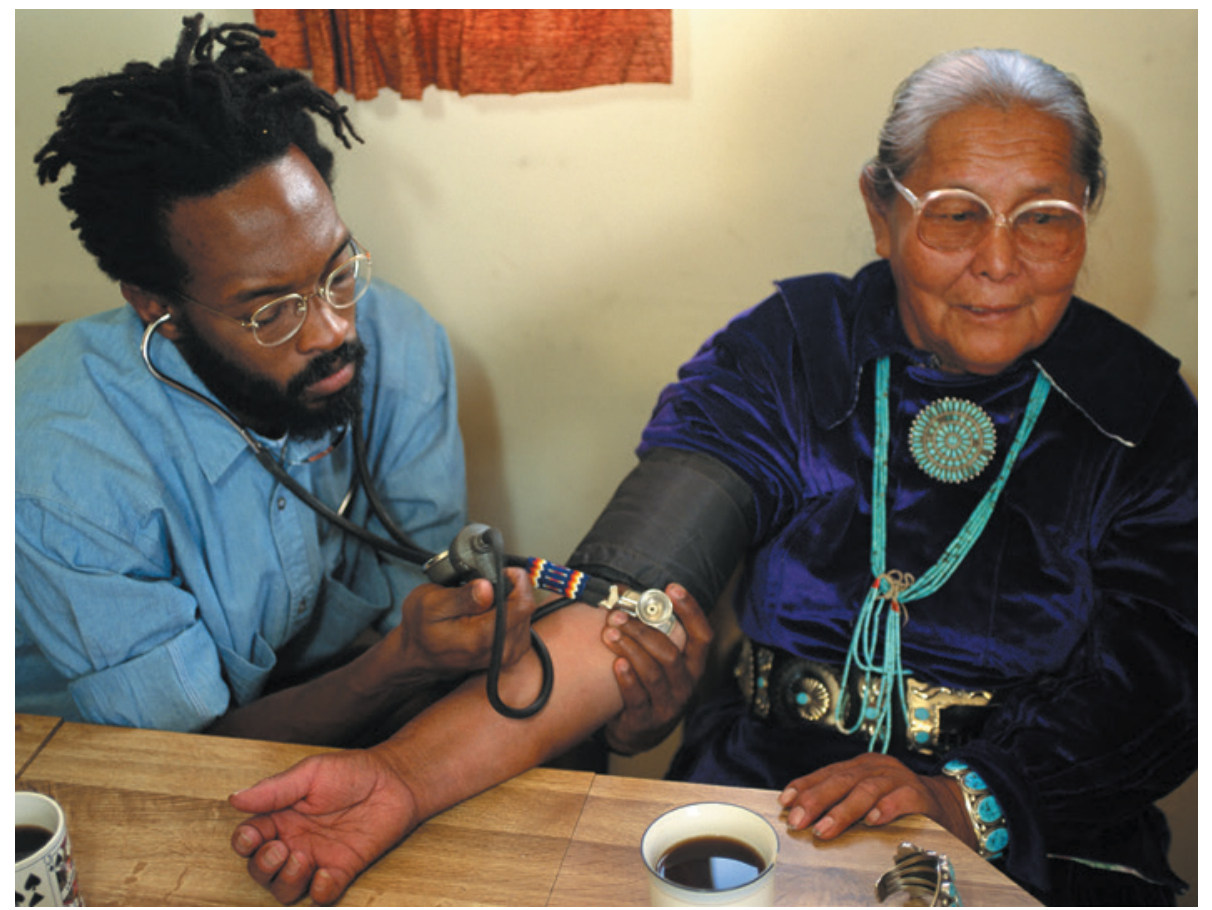

Clinical research in the United States does a poor job of including patients from minority groups.

"I would argue that it's a scientific question that needs to be addressed; it's not about the social reasons," adds Burchard, a member of the PMI working group. The team has decided to over-represent minority groups in the study relative to their share of the US population. Doing this should increase researchers' ability to draw statistically significant conclusions about small groups.

For example, alcoholism is particularly prevalent in Native American communities, and a study such as the PMI could help to reveal genetic and environmental factors that might underlie this vulnerability. But Native Americans make up just $1.6 \%$ of the US population, and if they were represented proportionally in a 1-million-person study, that would amount to just 16,000 participants - and focusing on subgroups determined by socio-economic status or age would further reduce the sample size.

Sarah Gehlert, who researches health disparities at Washington University in St. Louis, Missouri, hopes that the PMI will focus not only on ethnic minorities but

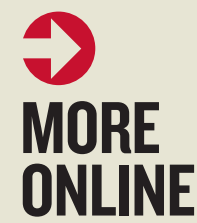

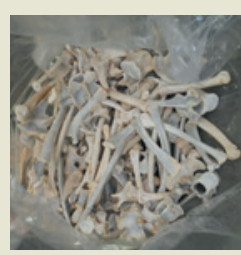

Crackdown on tiger trade boosts lion-bone sales go.nature.com/ zp9wlj

\section{MORE NEWS}

- Polar-bear metabolism cannot cope with ice loss go.nature.com/qg12ro - Quiz: test your knowledge about the week in science go.nature.com/oixntq - World Health Organization to recommend early treatment for everyone with HIV go.nature.com/kbytsp

\section{NATURE PODCAST}

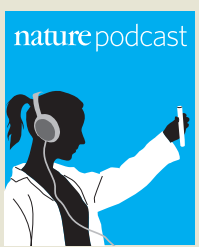

RNA's twists and turns, eyedrops replace cataract surgery, and farming climatefriendly rice nature. com/nature/podcast 
- also on other under-represented groups, such as poor people and those in rural areas. When minorities are included, they tend to be upper-class, educated and urban. But recruiting and retaining members of underrepresented groups presents a challenge - they may not have the resources to find information about the study online, and may lack experience

"Just because you can study patients at an ivory-tower academic institution doesn't mean you can do it in rural Appalachia." in using the fitness trackers and mobile apps with which the PMI plans to collect physiological data.

The NIH has not yet decided how it will recruit PMI participants. Gehlert is concerned that the agency could rely too heavily on patient-advocacy organizations such as breast-cancer support groups, which tend to attract white, affluent city dwellers. She also notes that the PMI plans to use data from medical records. Because poor people are more likely to seek care at emergency departments than to have regular doctors, their records are often fragmented.

Such people are also more likely to be distrustful of researchers. "Just because you can study patients at an ivory-tower academic institution doesn't mean you can do it in rural Appalachia," Burchard says. With this in mind, the NIH is consulting researchers experienced in recruiting under-represented groups into clinical trials.

At the PMI working group's meeting on 2 July, public-health researcher Donna Antoine-LaVigne of Jackson State University in Mississippi talked about her work with the 5,300-participant Jackson Heart Study, the largest survey of cardiovascular disease in African Americans. It includes both urban and rural populations, and has relied heavily on health workers going into their own communities to recruit participants.

Although this approach is labourintensive, Antoine-LaVigne believes that it is cost-effective. "Having people on the ground that do this would cost a lot less in the long run, because otherwise you're taking investigators away from their research," she says. "And a lot of them don't have a clue about bringing folks in."

Striking a balance between communitybased approaches and conventional research studies at hospitals or universities is a priority for the PMI working group, says its co-chair Bray Patrick-Lake, who works in patient engagement in research at Duke University in Durham, North Carolina. The NIH has not decided how to allocate the project's resources, but "I don't see this as a landscape for only the traditional players in research", she says. -

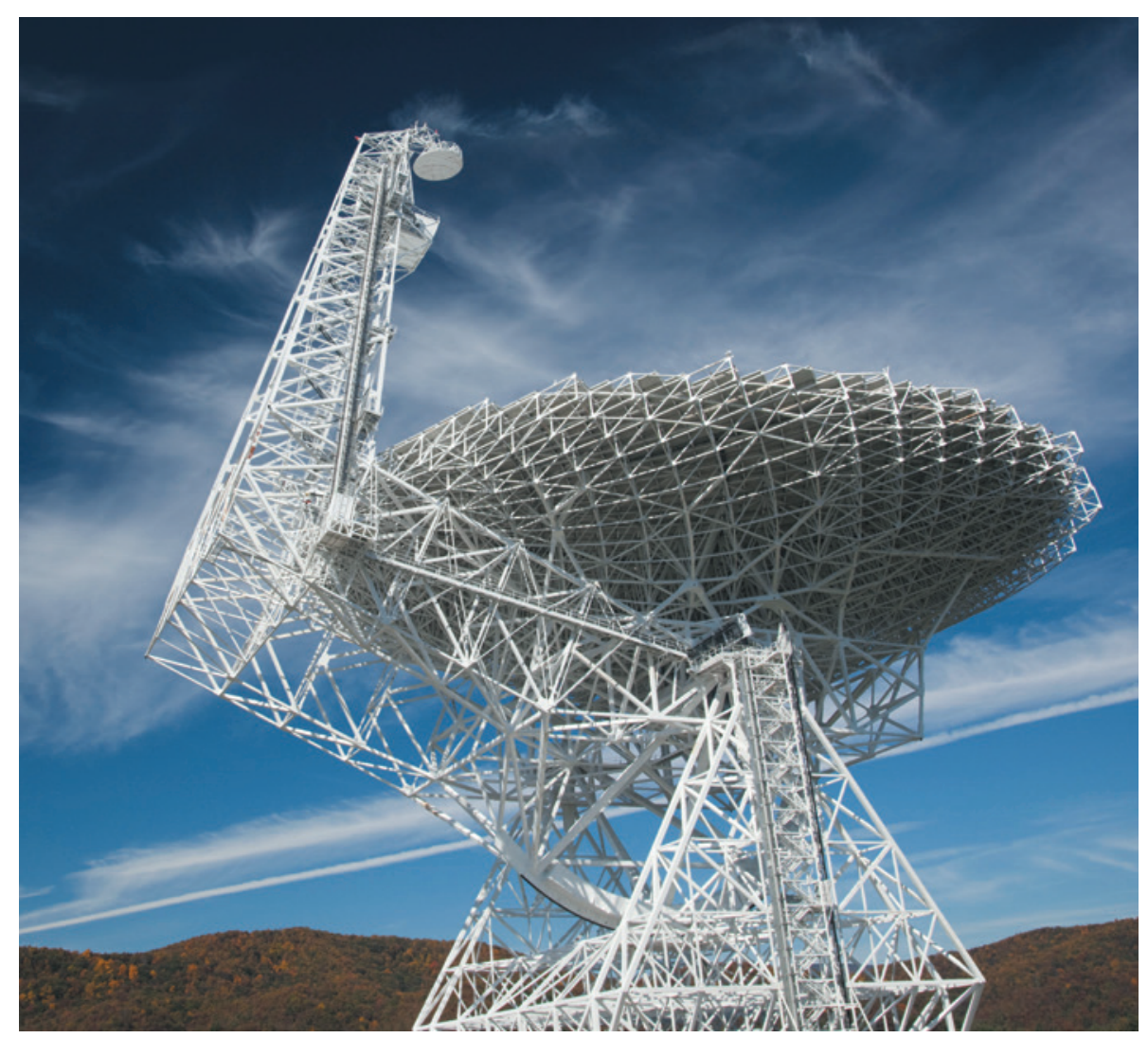

The Green Bank telescope in West Virginia is one of three that will search for extraterrestrial intelligence.

\section{ASTRONOMY}

\section{Hunt for alien life gets cash bonanza}

\section{US\$100-million SETI project will buy years of telescope time.}

\section{BY ZEEYA MERALI}

Y ou could say that the silence has been deafening. Since its beginnings more than half a century ago, the dedicated search for extraterrestrial intelligence (SETI) has failed to detect the presence of alien civilizations. But at London's Royal Society on 20 July, Russian billionaire Yuri Milner announced a shot in the arm for SETI: a US\$100-million decadal project to provide the most comprehensive hunt for alien communications so far.

The initiative, called Breakthrough Listen, will see radio telescopes at Green Bank in West Virginia, the Parkes Observatory in Australia and the Lick Observatory's optical telescope in San Jose, California, scanning around one million stars in the Milky Way and 100 nearby galaxies. "We would typically get 24-36 hours on a telescope per year, but now we'll have thousands of hours per year on the best instruments," says one of the project leaders, Andrew Siemion, a SETI scientist at the University of California, Berkeley. "It's difficult to overstate how big this is. It's a revolution."

Milner is also releasing an open letter backing the idea of an intensified search; it has been co-signed by numerous scientists, including physicist Stephen Hawking. "In an infinite Universe, there must be other life," Hawking told luminaries at the launch event. "There is no bigger question. It is time to commit to finding the answer."

SETI projects usually search for radio or optical signals that seem to be from an artificial source, for instance because they are focused in frequency and repeat in a regular manner. But funding has been patchy: in the early 1990s, NASA sponsored some searches, but dropped that support in 1993. "In recent years, the total worldwide support for SETI was about 
half a million dollars, mostly in the United States, and all from private gifts," says Frank Drake, one of the pioneers of modern SETI, who is also on the Breakthrough Listen team. "Now we're getting $\$ 100$ million, so that's real progress."

Milner, who is bankrolling the project, made his fortune through investments in Facebook and other Internet businesses, and in 2012 established the lucrative 'Breakthrough' prizes to reward excellence in the life sciences, fundamental physics, and mathematics. A particle-physics graduate, he jokes that his interest in SETI began in 1961, the year of his birth; he was named after Russian cosmonaut Yuri Gagarin, instilling a lifelong fascination with space and the possibility of alien life.

\section{DATA TORRENT}

The small SETI community will be inundated with a torrent of data - potentially as much in a day as earlier SETI projects collected in a year, Milner estimates. The data will be publicly available, to allow enthusiasts to join the search; Breakthrough Listen will also partner with the established SETI@home project that connects people's home computers and uses them to crunch data. "The results belong to everyone equally," says Milner, adding that transparency is particularly important in a project searching for aliens because "there are so many conspiracy theorists”.

Drake argues that Breakthrough Listen will have a positive impact on the wider astronomy community. The investment has saved the relatively old Green Bank and Parkes telescopes from the threat of closure, he says, as governments divert funds to larger-scale, higher-resolution projects such as the Square Kilometre Array (SKA). The sky survey might discover more pulsars, and help to home in on the origin of mysterious 'fast radio bursts' — pulses lasting only a few milliseconds.

Breakthrough Listen has not finalized its search strategy, but one of the project's first tasks will be to fully scan stars for signals in the frequency band between about 1 and 10 gigahertz. The band has been identified in the past as a good channel for deliberate alien communication because signals can travel through interstellar space and Earth's atmosphere without much interference. "Previously we've only been able to hunt and peck at it, now we'll search that entire spectrum comprehensively," says Siemion.

"It's quite likely that we won't find anything," Milner concedes, adding that a negative result would allow astronomers to put some limits on what is out there. "But in ten years' time, there will be even more advances and we can work out the best strategy for the next ten years of the project, and then maybe the next ten after that," he says. -

\section{Teen is healthy 12 years after ending HIV drugs}

\section{Case is longest remission after treatment in a child.}

\section{BY ERIKA CHECK HAYDEN}

A French 18-year-old who was infected with HIV at birth remains in good health despite taking her last dose of antiretroviral drugs 12 years ago. Her exceptional case is the longest-lasting example of a person infected at birth suppressing the virus after stopping treatment, and has revived some of the optimism that was crushed when the 'Mississippi baby' - who was apparently cured of HIV in 2013 by early and aggressive treatment - relapsed after just over two years (see Nature http://doi. org/w2n; 2014).

"At some point, the idea of remission was mixed with the idea of cure, and expectations were too high," says translational researcher Asier Sáez-Cirión of the Pasteur Institute in Paris, who presented the French teenager's case on 20 July at the annual meeting of the International AIDS Society in Vancouver, Canada. He says of the girl's family: "They understand that this is not a cure, that this is a state of remission, and that we don't know exactly what happened."

The case intrigues researchers who hope to learn more about HIV and how best to control it using antiviral drugs. Those in the field would like to know whether there are characteristics that might be used to predict which people will fare well if their treatment is discontinued. French researchers are following 20 adults, known as the VISCONTI cohort (A. Sáez-Cirión et al. PLoS Pathogens 9, e1003211;2013), a group of 'post-treatment controllers' who have been able to suppress the virus after being off antivirals for a median length of 10 years.

These cases are distinct from those of 'elite controllers' - the roughly $1 \%$ of people with HIV who can keep the virus in check despite never starting treatment. That group shows distinct genetic and immunological characteristics compared to post-treatment controllers.

"It seems like something is different" between post-treatment and elite controllers, says virologist Steven Deeks of the University of California, San Francisco. But, he says of the French teenager and other post-treatment controllers, "it's impossible to prove that they would not have done well in the absence of therapy."

Sáez-Cirión reported that, like those in the VISCONTI cohort, the French girl has particular variants of immune-system genes that seem to have predisposed her to particularly severe early HIV infection. Researchers are not sure how this might be connected to the ability to control the virus for several years after discontinuing treatment. One possibility is that the gene variants may cause their infections to be noticed sooner than in other people with HIV, and thus they can be treated earlier in the development of their disease.

Like the Mississippi baby, the French teen became infected by her mother around the time of birth. But there are some crucial differences between the timing and dosing of the treatment regimens that the two children received.

"This is not
acure, this
is a state of
remission, and
we don't know
exactly what
happened."

The US baby was given highly active antiretroviral therapy - a combination of powerful medicines designed to control HIV - within 30 hours of birth. By contrast, the French girl was initially treated for six weeks with a single drug, zidovudine. When her viral load shot up at the age of three months, she started a combination treatment with four antiretroviral drugs.

But her family decided, for reasons that have not been made public, to discontinue her treatment when she was between five and six years old. Even so, when doctors saw her as a six-year-old, she was apparently healthy, with an undetectable level of HIV in her body. Twelve years later, she is still healthy despite not taking any further medication for HIV.

"It's an intriguing case, but it's a very unique and unusual outcome," says physician and virologist Deborah Persaud of Johns Hopkins Children's Center in Baltimore, Maryland, who first reported on the Mississippi baby in 2013 (see Nature http://doi.org/m2d; 2013). "We've had many kids who are treated for years, then go off treatment and rebound, so the global message is still that kids should stay on treatment."

The French teenager is now being studied as part of the VISCONTI cohort. Eighteen of the study participants remain drug-free. In general, only $5-15 \%$ of people who start early treatment are able to remain in control of the virus in this way after discontinuing treatment. 


\section{NUCLEAR NEGOTIATIONS}

\section{Iran deal welcomed}

Agreement good for science.

\section{BY DAVIDE CASTELVECCHI}

$\mathrm{T}$ he agreement between six world powers and Iran over its nuclear programme is a historic step towards normalizing Iran's international relations - and has potentially profound implications for science.

"The agreement as a whole will surely have far-reaching consequences for science in Iran," says Reza Mansouri, an astronomer at the Institute for Research in Fundamental Sciences (IPM) in Tehran and a former deputy science minister of Iran.

Should the deal - signed on 14 July in Vienna - hold up, it would ease sanctions that have crippled Iran's economy in return for steps to ensure that the country's nuclear programme is used for peaceful means. "International collaborations have taken a very serious dip during the sanctions," says Shahin Rouhani, a physicist at the IPM and president of the Physics Society of Iran. Once restrictions lift, he says, travel will become easier for Iranians who are participating in conferences overseas and for foreign scientists who are visiting Iran. Labs there should find it simpler to order equipment from abroad.

The sanctions have made it difficult for Iran to participate in international collaborations such as SESAME, a synchrotron light source that is under construction in Jordan and whose members include Turkey, Pakistan, Israel and several Arab countries. Herman Winick, a physicist at Stanford University in California and a member of the SESAME Scientific Advisory Committee, says that lifted restrictions on banking activities should enable Iran to make the payments that it has pledged to the project.

As part of the deal, Iran also committed to converting one of its major sites for enriching uranium, an underground facility in Fordow, into a physics laboratory. The tunnels at Fordow could, for instance, house a particle accelerator or detectors for studying cosmic rays or neutrinos; any remaining centrifuges might be repurposed to produce isotopes for use in medical imaging. Mansouri says that it is too early to discuss concrete prospects for what physics might happen at Fordow, however.

The Vienna agreement must first survive political challenges - particularly in the US Congress - and its success will ultimately depend on international observers certifying Iran's compliance.

See go.nature.com/oinqcx for more.

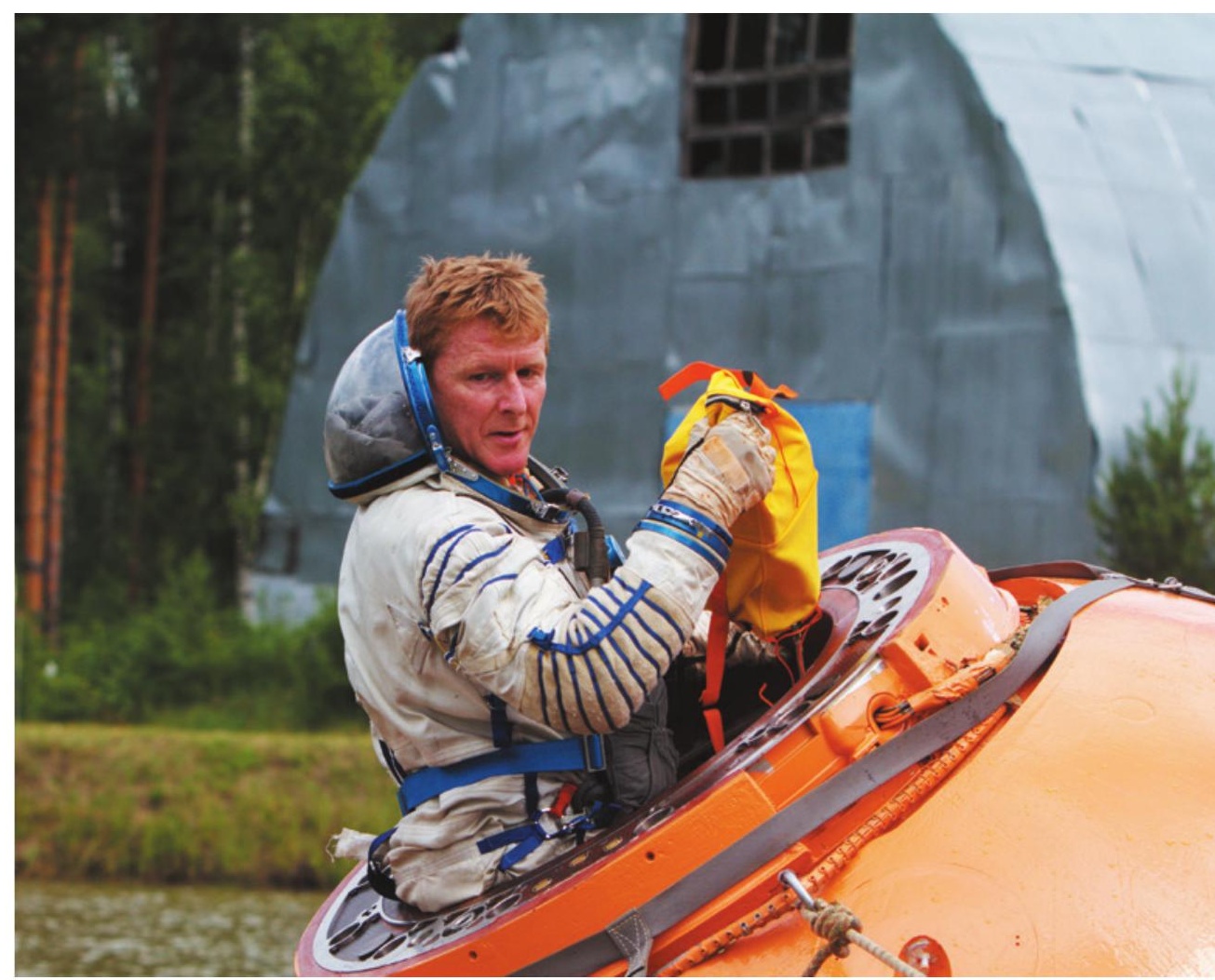

British astronaut Tim Peake will board the International Space Station later this year.

SPACE SCIENCE

\section{Britain shifts its}

space strategy

\section{UK research surrounding human spaceflight is booming.}

\section{BY ELIZABETH GIBNEY LIVERPOOL, UK}

$\mathrm{W}$ hen Tim Peake enters the airlock of the International Space Station (ISS) in December, the former helicopter pilot will become the first astronaut to fly backed by the UK government. When, or if, other Britons will follow is unclear, but the milestone represents a wider change to the focus of UK space science.

"It does feel like an awful long time that the UK has been closed to human spaceflight," said former astronaut Helen Sharman at the UK Space Conference 2015 in Liverpool on 13-15 July. "Now the lid has well and truly been lifted, and it's clear how much interest has been just bubbling under the surface." Sharman became the first Briton in space when she flew to the Mir space station in 1991 as part of a Russian space mission with sponsorship from private companies.
Britain has long contributed to European Space Agency (ESA) programmes involving robotic probes and space telescopes, which tend to focus on astronomy and planetary science. But it is the only country of the G8 industrialized nations not to have put an astronaut on the ISS. The United Kingdom began to extend its space interests in 2012, when it pledged $€ 20$ million (US\$22 million) to the ISS and $€ 16$ million over four years for ESA's European Programme for Life and Physical Sciences (ELIPS), which does experiments on the ISS and other platforms that take advantage of the space environment, including the effects of microgravity, radiation and an extreme vacuum. An extra $£ 49.2$ million (US\$76 million) for the spacestation programme followed in 2014.

The contribution to ELIPS allows British scientists to lead the teams that compete for the programme's grants, a development that seems to have increased 
क their participation. Before 2012, around 20 UK scientists participated in ELIPS experi-

o ments. Now the figure is close to 100, says Andrew Kuh, manager of the human spaceflight and microgravity programme at the UK Space Agency. "The uptake has been massive."

The scientists seem to be making their mark. UK research teams took the two top places in a ranking of the latest applications for new European life-sciences experiments to be carried out on the ISS. "That [achievement] is from a standing start, not having been involved before," notes Kuh. One of the teams, led by Donna Davies at the University of Southampton, UK, plans to build a 3D model of human bronchi to see how a lack of gravity affects the respiratory system. The project offers clues to the United Kingdom's speedy success, says Simon Evetts, a physiologist at the aerospace-medicine firm Wyle Laboratories in Cologne, Germany, who is contracted to work at the European Astronaut Centre there. "The UK has a fantastic biomedical heritage and strengths in aviation medicine," he says. "We can take these and apply them to the field of space and human spaceflight."

The creation of the UK Space Agency in 2010 helped to foster the new focus on spaceenvironment research, says Kuh. It was difficult for the United Kingdom to be involved before then because of the fragmented nature of the field: it spans fundamental physics and

materials science as well as biomedicine, which are all funded separately.

The UK Space Agency coordinates funding for research, rather than carrying it out, and is a smaller player than NASA or its European equivalents, such as the French space agency CNES, or the German Aerospace Center (DLR). But its size and relative youth mean that it is more nimble and

"We are entering a new space age with constellations of several hundred or thousands of satellites."

free of red tape, says Kuh. Chris Castelli, the agency's director of programmes, notes that unlike the CNES, the UK Space Agency is tasked with space policy. "We are entering a new space age with constellations of several hundred or thousands of satellites," he says. "What does that mean for the regulatory environment, for space-enabled services and systems? There's a whole load of stuff there we're well disposed to respond to."

Even counting its contributions to ELIPS and the ISS, the UK government still spends less on space as a proportion of gross domestic product than does Germany, France or Italy. JohannDietrich Wörner, who took over as directorgeneral of ESA at the start of July, believes that the UK government is focused on getting a direct return for its businesses from any investment, rather than on the "full chain of innovation", which includes fundamental research. "You have very smart scientists in the UK, and you have very good industrial partners," he says. "One should not focus on only one or the other."

Wörner commends one non-business area in which the UK government is hoping to cash in - education. Now that Britain is a contributor to the ISS programme, Peake can be claimed as a British astronaut, as well as a European one. And the government is backing a range of school programmes related to Peake's trip, during which he will be a guinea pig for more than 20 experiments probing physiology in space. Meanwhile, the UK Space Agency is funding research to measure whether the number of people studying science and engineering surges as a result of Peake's flight, as it did in the United States after the Apollo missions.

In the short term, Peake is likely to be a oneoff. "We're not going to have a UK astronaut corps anytime soon," says Kuh. But Sharman hopes that the government's interest in human spaceflight and the space environment will last. Although a national strategy for human spaceflight, released by the UK Space Agency on 6 July, suggests that Britain is not just dipping its toes into the water, Sharman is reserving judgement. A test will come next year when renewal of ELIPS funding is up for review. 